\title{
Open as Default: The Future of Education and Scholarship
}

\author{
Rajiv S. Jhangiani \\ Kwantlen Polytechnic University, rajiv.jhangiani@kpu.ca
}

The opposite of open is not closed; the opposite of open is broken. The more I think about it, the more this cogent observation, made by John Wilbanks, resonates with me

Scholarly publishing is certainly broken. Here, the farce that passes for tradition supplements public funding for researchers with generous dollops of (publicly subsidized) voluntary peer review and editorial work. The taxpayer is then asked to provide additional funding for database subscription fees so that institutions can access the very research they produce. And as if paying three times was not enough, if the very same taxpayer wished to access the fruits of all this labour, they would instead find a paywall. That is, unless the researcher had access to even more public funding to cover (often exorbitant) article processing charges (APCs).

Science is arguably broken. Here, tradition incentivizes trading off unsexy but cumulative research for flashy but non-reproducible findings. Worse still, the prevailing system encourages questionable research practices like $p$-hacking and withholding disconfirming data. Every new generation of scholars learns that prestige is associated with communicating in the least accessible style through the least accessible and impactful channels.

How to cite this book chapter:

Jhangiani, R S. 2017. Open as Default: The Future of Education and Scholarship. In: Jhangiani, R S and Biswas-Diener, R. (eds.) Open: The Philosophy and Practices that are Revolutionizing Education and Science. Pp. 267-279. London: Ubiquity Press. DOI: https://doi.org/10.5334/bbc.v. License: CC-BY 4.0 
Pedagogy too reveals many chips and cracks. Here, faculty routinely adapt their courses to map onto the structure of textbooks instead of the other way around. Lecturing remains popular, despite masses of empirical evidence that unequivocally show the advantages of higher impact practices such as active and experiential learning. Instructors still regularly assign 'disposable' assignments in which students produce work for one person while they in turn take pains to provide thoughtful feedback that is almost immediately recycled at the end of the term. And a great many educators continue to teach in a manner that assumes their principal role is that of content delivery, despite living in an age of unparalleled access to information.

Higher education, itself - if not broken - is certainly delusional. For how else can we describe an enterprise in which we continue to pretend that our students start and finish at the same place and at the same pace? Where we cling to the fantasy that our students have unfettered access to required course materials. Where our programs do not serve the modal student, who works at least part-time and will no longer spend four years studying full-time at the same institution. And where we claim to value being 'student-centered' when in practice faculty, course content, accreditation or testing requirements, and budgetary concerns drive the learning process far more than students.

All of this is why I bristle when I hear the old 'if it ain't broke, why fix it?' argument. For if it's not open, it is broken, and that's precisely why we must fix it.

\section{Open Access as Default}

A number of changes are needed in order for open access to become default practice. Government and other organizations that fund scholarship need to lead by requiring grantees to adopt open licensing for their publications (see Chapter 3 by Cable Green for the example of the US Department of Labor). At the very least, granting organizations need to mandate that copies of published manuscripts be placed in an open repository, even if after a short embargo period (see for example recent policies from the US National Science Foundation Open Access Policy or the Canadian Tri-Council Open Access Policy). More education and awareness is also needed with the issue of open access. Many scholars do not understand the differences between green (immediate self-archiving), gold/hybrid (APCs), and platinum (no APCs) open access. And still more equate open access journals with predatory journals that are happy to accept (in exchange for APCs) an article consisting solely of the phrase 'Get me off your fucking mailing list' repeated for ten pages (with accompanying flow charts and scatter plot graphs ${ }^{1}$ ).

Scholars need to work determinedly and collectively to challenge the status quo, to found and manage high quality open access journals. Chapter by Aaron Jarden and Dan Weijers provides an excellent example of this, as does the recent case of the mass resignation of the editors and editorial board of 
Lingua due to Elsevier's refusal to change its APC policies. ${ }^{2}$ In this latter case, the very same editorial team has since founded Glossa (published by Ubiquity Press, also the publisher of this book), a high quality open access journal with significantly lower APCs. Of course, given that scholars produce the research, provide the peer review, make the editorial decisions, and pay for the APCs, you might rightly think that we hold all of the power. But breaking with tradition in this fashion still requires taking a principled stand. This is most powerful when senior scholars (who typically hold grants and have the ability to pay high APCs) speak on behalf of junior (e.g., pre-tenure) scholars, who face the maximum pressure to publish in the highest impact journals in their field, and which may not provide an open access option. The irony of course is that articles published with an open access license are far more likely to be read and cited (SPARC Europe, 2016), and therefore actually have an impact.

\section{Open Science as Default}

Brian Nosek's description (Chapter 7) of a conversation with his young daughter about the differences between how science ought to function and how it actually does is the clearest and most evocative account I have come across of just how broken science is. I believe that if open science is to become default practice it will take a more radical shift, one driven by an ideological commitment to scientific progress ${ }^{3}$. Pre-registering one's hypotheses and data analysis plans will serve as a guard against $p$-hacking and hypothesizing after the results are known (HARKing). Sharing raw data in an open repository will deter the fabrication of data and the selective deletion of outliers. Sharing research materials and statistical syntax openly will facilitate replication. And designing and publishing careful, iterative, high-powered studies instead of single study publications with low statistical power will enhance rigour and replicability. Each of these practices needs to be incentivized or otherwise encouraged by the leadership and professional bodies within a discipline. Joining the more than 50 organizations and 500 journals that have adopted the Transparency and Openness Promotion (TOP) guidelines would be a good start.

In my discipline the Association for Psychological Science has been among the groups leading the shift to open ${ }^{4}$, with its flagship journal Psychological Science awarding digital badges to researchers who adopt such practices. Looking at individual scholars, however, there has been noticeably greater openness to open science among those at the Assistant or Associate Professor level. Interestingly, many of these young leaders, like Simine Vazire, Sanjay Srivastava, Daniel Lakens, and Will Gervais, are also active bloggers, reflecting on methodological issues and their resolution squarely in the public domain. And while it is easy for traditionalists to discount blogging as 'not real academic writing', these posts are widely shared and read, generating what is arguably a rapid and open peer review via posted comments. ${ }^{5}$ As with writing op eds, blogging is a high 
impact form of open scholarship (note that the average journal article is read completely by about 10 people;), ${ }^{6}$ one that is disincentivized by the academy and not easy or comfortable. ${ }^{5}$ It requires an ability to think deeply, write accessibly, and publish fearlessly, and is motivated precisely by a commitment to scientific progress.

That same commitment to scientific progress may also spur the mainstreaming of open peer review, which, despite potential drawbacks like greater difficulty locating reviewers and a slower peer review process, produces reviews that are of the same or higher quality while being more courteous. ${ }^{6}$ Indeed, according to Kriegeskorte:

Open evaluation goes hand in hand with a new culture of science. This culture will be more open, transparent, and community controlled than the current one. We will define ourselves as scientists not only by our primary research papers, but also by our signed reviews, and by the prior work we value through our public signed ratings. The current clear distinction between the two senses of 'review' (as an evaluation of a particular paper and as a summary and reflection upon a set of prior papers) will blur. Reviews will be the meta-publications that evaluate and integrate the literature and enable us as a community to form coherent views and overviews of exploding and increasingly specialized literatures. (2012: 12)

\section{Open Educational Resources as Default}

For open educational resources (OER) to become the default choice for the majority of faculty they will first need to learn of their existence. Unlike traditional publishers' textbooks, OER do not have a well-oiled marketing machinethere are no unsolicited and cumbersome packages clogging faculty mailboxes, no offers to sponsor research conferences or student events, no smiling faces knocking on office doors. Moreover, once faculty learn of the existence of OER, they must interact with and review these resources to combat the common myth that what is freely accessible must be of low quality (forgetting of course that they are not free to produce). Indeed, OER have come a long way from the days of long text-based .pdf documents with no images, learning aids, multimedia, or interactive features. OER are now increasingly commonly supported by a robust range of ancillary materials like test banks, lecture slides, and instructor manuals, which is why $85 \%$ of 2,366 students and 2,144 faculty (aggregated across 9 peer-reviewed studies) familiar with OER now rate their quality as the same as or better than traditional resources. ${ }^{7}$

Given the exorbitant cost of textbooks in North America, it is understandable that open textbooks have been sailing primarily under the flag of cost 
savings. However, all of the advantages of open textbooks need to be clearly understood and articulated, for although the cost to students is a factor that (some) faculty pay attention to, it is far from the primary consideration when adopting course materials. Indeed, one major survey suggests that it may be the least important criterion to adopting faculty. ${ }^{8}$ So faculty need to understand that while their students benefit from free, immediate, portable, and permanent access to required course materials, they too stand to benefit from the additional permissions to revise, remix, update, and contextualize the textbook to serve their pedagogical goals, and even embed and scaffold course assignments within the readings. And far from harming students, every single one of the thirteen peer-reviewed studies that has investigated OER efficacy has found that students using these resources perform the same as or better than those who are assigned traditional textbooks (see: http://openedgroup. org/publications).

Looking beyond course performance, data from a number of studies even show the positive impact of OER adoption on the number of credits enrolled in during subsequent semesters, and improved student retention and program completion rates. ${ }^{9}$ Taken together, OER thus represent a big win for students, a win for faculty, and even a win for institutions. This is why, despite the absence of traditional marketing, OpenStax books are now adopted by one out of every five degree granting institutions within the United States (see Chapter 17), open textbooks from the BC project are now adopted at all 25 public post-secondary institutions in the province, and institutional membership in the Open Textbook Network continues to grow rapidly. OER is slowly but surely going mainstream.

\section{Open Pedagogy as Default}

Driving an airplane down the road. That is the metaphor that David Wiley uses when describing traditional, 'disposable' assignments, ones that 'students complain about doing and faculty complain about grading. They're assignments that add no value to the world - after a student spends three hours creating it, a teacher spends 30 minutes grading it, and then the student throws it away.' ${ }^{10}$ Of course this assumes that the student retrieves the assignment at all, and, if they do, that they even briefly consider the feedback that the instructor has thoughtfully crafted.

While I take David's point, I confess that I do see value in many kinds of traditional assignments. I also recognize that most faculty aim to create engaging and authentic learning experiences for their students, ones that will allow them to become both knowledgeable and skillful, and to become good global as well as good local citizens. There is no shortage of good intent here, which is precisely what makes me optimistic. Although the use of fact-based 
multiple-choice questions drawn directly from publisher-supplied question banks is ubiquitous, a growing number of instructors are looking to harness the energy, potential, and even the creativity of their students in order to have them produce resources for the commons. However, the challenge of this approach is in designing assignments that:

1. allow students to develop and exercise useful skills that align well with course and program learning outcomes;

2. produce something that will add value to the world;

3. produce something that will be openly available;

4. provide sufficient support so that the experience will not be terrifying for them (a serious concern as we ask them to step outside of their comfort zones); and

5. build in enough latitude so that the assignment constitutes a creative project and not simple a recipe for the same product.

As seen in Chapter 9 by Robin DeRosa and Scott Robison, open pedagogy and especially the notion of students as creators inhabits a transformational and inspirational space in which faculty do not simply adopt open educational resources but instead adopt open educational practices. It is this kind of transformative thinking that lead Delmar Larsen and many of his colleagues at the University of California at Davis to harness the efforts of thousands of students over several years to first build ChemWiki (now the most visited Chemistry website in the world) and what is now the massive LibreTexts library. A source of customizable course materials and learning analytics for dozens of institutions, the LibreTexts library leaves behind the archaic practice of static 'editions' of textbooks, with these rapidly outdated snapshots of a discipline now replaced with a living, dynamic, flexible, and interactive body of knowledge. And although the resource is demonstrably efficacious ${ }^{11}$ and the cost savings for students are substantial, these traditional arguments for OER are now the encore as the pedagogy takes centre stage.

If open pedagogy is ever going to go mainstream several questions remain: is OER adoption a gateway to open pedagogy, as some claim? Given that it is far easier to place technology in people's hands than it is to get people to do things differently, how many potential OER adopters would actually take advantage of the license to revise and remix, or even involve their students in OER creation? If some are attracted to OER principally out of a concern for social justice whereas others are drawn by the potential for pedagogical innovation, the overlap between these two sets may well be labeled a gateway. But surely people differ not only in their awareness of open practices but also in their openness to practice. What are the implications of this heterogeneity within the open community and among our audience? These are all strategic and empirical questions that the field needs to grapple with. 


\section{Colonisers and Edupunks Unite}

Shortly after the 2015 Open Ed Conference in my hometown of Vancouver, BC, Robert Farrow (a co-author of Chapter 5) wrote a blog post reflecting on the emergence of 'Coloniser' and 'Edupunk' subcultures within the open education community, those who aim to displace traditional textbooks by emphasizing free versus those who aim to transform pedagogy by emphasizing freedom. The language of social justice, access to resources, and open textbook efficacy belong to the former whereas discussions about innovative teaching practices, access to ideas, and open pedagogy belong to the latter. Evolution in education versus revolution in education.

Robin DeRosa, undoubtedly among the revolutionaries and a co-author of Chapter 9, had implored us to 'stop fetishizing the textbook, which is at best a low-bar pedagogical tool for transmitting information. OER is better than that.' Amanda Coolidge (Senior Manager, Open Education at BCcampus), on the other hand, reminded us that although 'we come to open for different reasons ... yet for students, it is about cost. We have to remember that although we may be at the stage in open where we need to start talking and implementing open pedagogy many in the movement still care deeply about reducing student costs, and those are our student leaders. Students care about access and for students access to education means reducing financial barriers.'

Of course as framed here this is certainly a false dichotomy, as most people will fall somewhere in between the extremes of the Coloniser-Edupunk spectrum, and the pragmatism of the Colonisers likely affords the idealism of the Edupunks. I agree that there is something unsettling about promoting a free and open version (even with the ' $5 \mathrm{R}$ ' permissions to reuse, revise, remix, retain, and redistribute) of a resource that itself is a dinosaur and in desperate need of rehabilitation. As David Wiley notes in Chapter 15, 'Until the full stack of our intellectual infrastructure becomes open, truly democratized innovation and permissionless innovation will be impossible.' However, it is also true that open textbook adoption does allow students to gain in terms of both cost savings and educational outcomes (at least for those who would not have otherwise purchased an exorbitantly priced 'required' textbook). And as Amanda points out, these outcomes are incredibly valuable.

What is more, Edupunks vs. Colonisers is not the only example of subcultures within the open education community. Take the case of Creative Commons licenses, which, to the uninitiated, can resemble hieroglyphics (see Cable Green's chapter in this volume for a key). Working from within the movement, however, can make them appear more like gang signs, with purists (including some contributors to this volume) vehemently advocating against the adoption of the non-commercial (NC) clause for reasons that range from a lack of clarity about what it means to a respect of the right to sell or profit from 
OER (including as a pathway to sustainability for the movement). On the other hand, there are others (including many new initiates) who adopt more restrictive licenses because they derive comfort from knowing that their work cannot be stolen and sold by traditional publishers (NC) or modified by others, potentially sullying their reputation if errors are introduced (no-derivatives; ND). And while it may simply take greater experience in the open arena to enhance confidence and reduce territoriality (once again, an empirical question), I am convinced that the open education movement will benefit from welcoming as many into our big tent as possible. Doing so necessitates respecting the creator's choice of license without judgment or snobbishness and recalling that the movement itself is predicated on inclusiveness, freedom, and generosity.

In my opinion what would be far more useful than forming factions with different battle cries would be recognizing and responding in a nuanced fashion to the heterogeneity present in our audience. This is an analysis for which I have found the pencil metaphor (an adaptation of Rogers' theory of diffusion of innovation for the ed tech context) to be especially useful (see Figure 1).

The leaders adopt a new innovation, driven by intrinsic motivations and willing to experiment and fail. The sharp ones learn about what the leaders are up to, get excited by the proof of concept and begin to adopt the innovation themselves. Together the leaders and the sharp ones form small pockets of innovation that persevere despite the absence of support (and sometimes in the face of opposition).

As an advocate for openness, my audience is usually the wood-the ones who represent the mainstream (you grip the wood of the pencil, after all). These include scholars who 'would' publish openly if the highest impact journals of

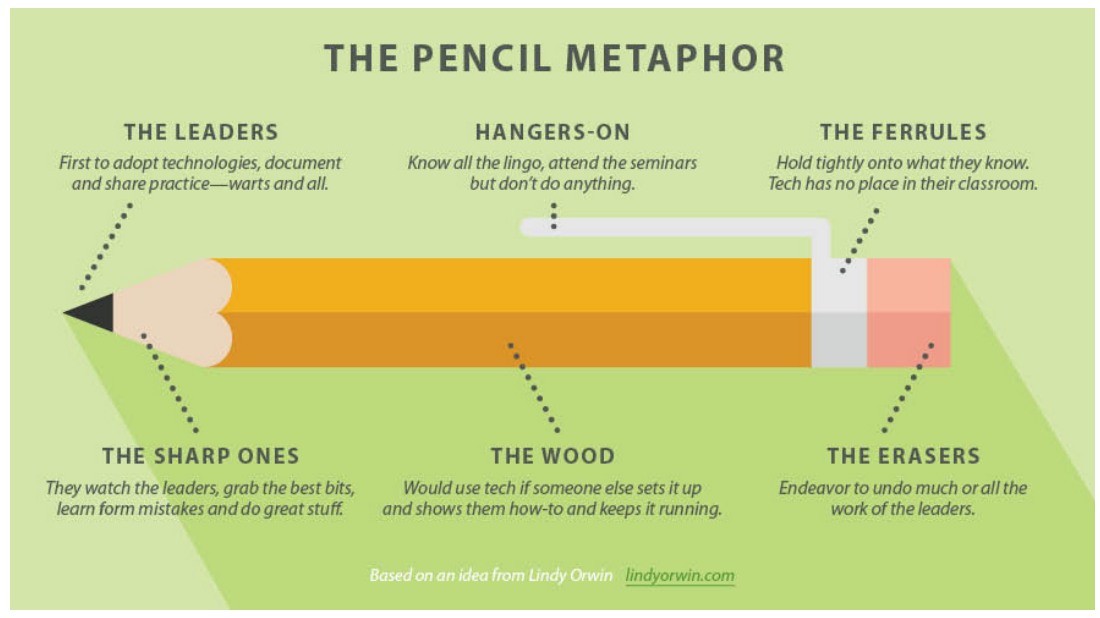

Fig. 1: "The pencil metaphor" by The William and Flora Hewlett Foundation is licensed under CC BY 4.0. 
their field were open access or did not demand high article processing charges to grant open access. Those who 'would' share their raw data or research materials (but only when directly requested). And instructors who have never heard about OER but who 'would' adopt open textbooks if they were available for their subject area, were easily accessible, were accompanied with a suite of ancillary resources, were of sufficiently high quality, and had demonstrated efficacy. Or so they say. For one challenge with advocacy involves distinguishing the wood, who may have sincere, rational criteria that they wish to be satisfied prior to going open, from the ferrules, who raise fairly disingenuous objections (e.g., where is the efficacy research for OER?). You know, those criteria that, once met, are swiftly replaced by another set. Together with the erasers, the ferrules are occasionally the most vocal in the group.

One of the strangest things about the battle for open is that so much territory, so much of our teaching and learning environment, has long-since been ceded. This is why describing the ability to revise course materials to map onto one's pedagogical goals as a layer of academic freedom carries a feeling of novelty. Or why when an academic department's textbook selection committee shortlists half a dozen titles, allows for idiosyncratic blackballing, and ends up with the text everyone can all live with, this does not feel like a concession. Because for most faculty these are not spaces in which there is any real expectation of academic freedom. While this acutely reveals the intimate relationship between one's philosophy of teaching and one's openness to openness, herein lies the key to establishing open as default:

For faculty who enjoy experimenting and innovating with teaching, OER adoption is indeed a meagre position to advocate. These are the folks who will enjoy playing with authentic and open pedagogy, who may actually take full advantage of the ability to revise and remix, and understand that adopting open educational practice is really just about good pedagogy and in that sense is not at all radical. Similarly, for those writing and practicing at the cutting edge of science, facilitating greater sharing-of data, materials, and articles-is likely to be greeted with gratitude and even relief. Scrutinizing the wood, I observe faculty who currently adopt high-priced, static textbooks but care enough about their students to feel guilty about this decision (principled agents in a principal-agent dilemma?). In at least some of these cases, the ensuing guilt leads them to bend the course to map onto the textbook. While not an example of great pedagogy, this could be construed as an empathic response that ameliorates both their guilt and their students' resentment. This is the region of the wood where the social justice case for open textbooks may resonate particularly well. The same might be said for making a principled case for open access among scholars who already (illegally) share copies of their pay walled publications with their peers and on websites like Academia.edu or Researchgate.

There are numerous gateways to open, many ways in which this core philosophy and common set of values may be activated. ${ }^{12}$ Adopting OER may serve as a gateway to adapting or even creating OER. Adopting OER for one 
course may serve as a gateway to adopting OER for other courses. One faculty member within a department adopting OER may serve as a gateway to other faculty adopters. One department adopting OER may serve as a gateway to other departmental adoptions within the same university or even region, or to the development of ' $Z$ degree' programs. Adopting OER may be a gateway to open pedagogy. Open access publishing may serve as a gateway to OER adoption. And practicing open science may serve as a gateway to practicing open pedagogy. Vice versa, in omnibus causis, ad infinitum.

\section{A Final Comment}

I am unabashedly an optimist about the future of open. I believe that this shift is not just desirable and moral but also inevitable. After all, open access would be a good idea even without prohibitive APCs, open science would be a good idea even without data fabrication, and OER would be a good idea even without exorbitant textbook costs, although each of these problems makes the shift more urgent. At their heart, both education and science are about service through the creation, sharing, and application of knowledge, goals that are compromised by traditional practices that are closed and broken. This is why I believe that the future of both education and scholarship is open. I see it on the horizon.

\section{Notes}

1 Mazieres \& Kohler, 2005.

2 Jaschik, 2015.

${ }^{3}$ We are already in the midst of a massive shift from the use of exorbitantly priced and proprietary (and surprisingly deficient) statistical software packages like IBM's SPSS to free and open source (and remarkably powerful) software packages like $R$; however, this shift appears to be primarily driven by its favourable position on the cost and quality axes.

4 The APS has also supported the open access publication of this book, through a small grant from its Fund for Teaching and Public Understanding of Psychological Science.

${ }^{5}$ Heleta, 2016.

${ }^{6}$ van Rooyen et al., 1999; Walsh et al., 2000.

7 Hilton, 2016.

${ }^{8}$ Allen \& Seaman, 2014.

9 Fischer et al., 2015; Hilton \& Laman, 2012.

${ }^{10}$ Wiley, 2013.

11 Allen et al., 2015.

12 Weller, 2014. 


\section{References}

Allen, E., \& Seaman, J. (2014). Opening the curriculum. Babson Survey Research Group. Retrieved from http://www.onlinelearningsurvey.com/reports/ openingthecurriculum2014.pdf

Allen, G., Guzman-Alvarez, A., Smith, A., Gamage, A., Molinaro, M., \& Larsen, D. S. (2015). Evaluating the effectiveness of the open-access ChemWiki resource as a replacement for traditional general chemistry textbooks. Chemistry Education Research and Practice, 16(4), 939-948. Retrieved from http://pubs.rsc.org/is/content/articlehtml/2015/rp/c5rp00084j

Biswas, A. K., \& Kirchher, J. (2015, April 11). Prof, no one is reading you. The Straits Times. Retrieved from http://www.straitstimes.com/opinion/profno-one-is-reading-you

Center for Open Science. (2015). The transparency and openness promotion guidelines. Retrieved from http://cos.io/top

Coolidge, A. (2015, November 23). Riffin' on the open textbook. [Web log comment]. Retrieved from https://gotcurls.wordpress.com/2015/11/23/riffinon-the-open-textbook/

DeRosa, R. (2015, November 20). Open textbooks? UGH. [Web log comment]. Retrieved from http://robinderosa.net/uncategorized/open-text books-ugh/

Farrow, R. (2015, November 28). Colonisers and edupunks (\&c.): Two cultures in OER? [Web log comment]. Retreived from https://philosopher1978.word press.com/2015/11/28/colonisers-and-edupunks-c-two-cultures-in-oer/

Fischer, L., Hilton, J., Robinson, T. J., \& Wiley, D. A. (2015). A multi-institutional study of the impact of open textbook adoption on the learning outcomes of post-secondary students. Journal of Computing in Higher Education, 27(3), 159-172. Retrieved from http://link.springer.com/ article/10.1007\%2Fs12528-015-9101-x

Gervais, W. (2016). Homepage. [Web log comment]. Retrieved from http:// willgervais.com/blog/

Government of Canada. (2015, February 27). Tri-Agency open access policy on publications. Retrieved from http://www.science.gc.ca/default.asp?lang= En\&n=F6765465-1

Heleta, S. (2016, March 8). Academics can change the world - if they stop talking only to their peers. Retrieved from https://theconversation.com/academicscan-change-the-world-if-they-stop-talking-only-to-their-peers-55713

Hilton, J. (2016). Open educational resources and college textbook choices: A review of research on efficacy and perceptions. Educational Technology Research and Development. 64, 1-18. DOI: https://doi.org/10.1007/s11423016-9434-9 Retrieved from http://link.springer.com/article/10.1007/s11423016-9434-9

Hilton III, J., \& Laman, C. (2012). One college'suseofanopen psychologytextbook. Open Learning: The Journal of Open, Distance and E-Learning, 27(3), 265- 
272. https://doi.org/10.1080/02680513.2012.716657 Retrieved from http:// scholarsarchive.byu.edu/cgi/viewcontent.cgi ?article $=1069 \&$ context $=$ facpub

Jaschik, S. (2015, November 2). Language of protest. Inside Higher Education. Retrieved from https://www.insidehighered.com/news/2015/11/02/editorsand-editorial-board-quit-top-linguistics-journal-protest-subscription-fees

Kriegeskorte, N. (2012). Open evaluation: A vision for entirely transparent post-publication peer review and rating for science. Frontiers in Computational Neuroscience, 6. DOI: https://doi.org/0.3389/fncom.2012.00079 Retrieved from: https://www.ncbi.nlm.nih.gov/pmc/articles/PMC3473231/ Lakens, D. (2016). The 20\% statistician. [Web log comment]. Retrieved from http://daniellakens.blogspot.ca/

Mazieres, D., \& Kohler, E. (2005). Get me off your fucking mailing list. Retrieved from http://www.scs.stanford.edu/ dm/home/papers/remove.pdf

National Science Foundation. (2015, March 18). National Science Foundation announces plan for comprehensive public access to research results. Retrieved from https://www.nsf.gov/news/news_summ.jsp?cntn_id=134478

Open Education Group. (n.d.). Publications. Retrieved from http://opened group.org/publications

Scholarly Open Access. (2016). List of publishers. Retrieved from: https://scholar lyoa.com/publishers/

SPARC Europe. (n.d.). The open access citation advantage service. Retrieved from http://sparceurope.org/oaca/

Srivastava, S. (2016, August 23). The hardest science. [Web log comment]. Retrieved from https://hardsci.wordpress.com/

Stafford, T., \& Bell, V. (2012). Brain network: social media and the cognitive scientist. Trends in Cognitive Sciences, 16(10), 489-490. https://dx.doi.org/10.1016/j. tics.2012.08.001 Retrieved from http://www.tomstafford.staff.shef.ac.uk/ docs/stafford_and_bell2012.pdf

Thierer, A. (2014, November). Embracing a culture of permissionless innovation. Retrieved from http://www.cato.org/publications/cato-online-forum/ embracing-culture-permissionless-innovation

van Rooyen, S., Goodlee, F., Evans, S., Black, N., \& Smith, R. (1999). Effect of open peer review on quality of reviews and on reviewers' recommendations: A randomised trial. BMJ Clinical Research, 318, 23-27. Retrieved from https:// www.researchgate.net/profile/Richard_Smith61/publication/13415327_ Effect_of_open_peer_review_on_quality_of_reviews_and_on_reviewers'_ recommendations_a_randomised_trial/links/54100e410cf2df04e75a55a6.pdf

Vazire. S. (n.d.). Sometimes I'm wrong. [Web log comment]. Retrieved from http://sometimesimwrong.typepad.com/wrong/

von Hippel, E. E.(2005), Democratizing Innovation. Cambridge, MA: MIT Press. Retrieved from http://web.mit.edu/evhippel/www/democ1.htm

Walsh, E., Rooney, M., Appleby, L., \& Wilkinson, G. (2000). Open peer review: A randomised controlled trial. The British Journal of Psychiatry, 176(1), 
47-51. DOI: https://doi.org/10.1192/bjp.176.1.47 Retrieved from: http:// bjp.rcpsych.org/content/176/1/47.long

Weller, M. (2014). The battle for open: How openness won and why it doesn't feel like victory. London, UK: Ubiquity Press. DOI: https://dx.doi.org/10.5334/ bam Retrieved from http://www.ubiquitypress.com/site/books/detail/11/ battle-for-open/

Wikipedia. (2016). Principal-agent problem. Retrieved from https:// en.wikipedia.org/wiki/Principal\%E2\%80\%93agent_problem

Wilbanks, J. (2010, August 13). The unreasonable effectiveness of open data. Retrieved from https://dspace.library.colostate.edu/bitstream/handle/10217/ 81403/CI_Days_2010_Wilbanks.pdf

Wiley, D. A. (2013, October 21). What is open pedagogy? [Web log comment]. Retrieved from http://opencontent.org/blog/archives/2975 